\title{
Correction: Cumulative inactivation of Nell-1 in Wnt1 expressing cell lineages results in craniofacial skeletal hypoplasia and postnatal hydrocephalus
}

\author{
Xiaoyan Chen · Huiming Wang • Mengliu Yu • Jong Kil Kim • Huichuan Qi • Pin Ha - Wenlu Jiang • Eric Chen • \\ Xiangyou Luo · Ryan Brent Needle · Lloyd Baik • Cathryn Yang • Jiejun Shi • Jin Hee Kwak • Kang Ting • Xinli Zhang • \\ Chia Soo
}

Published online: 23 March 2020

(c) The Author(s), under exclusive licence to ADMC Associazione Differenziamento e Morte Cellulare 2020

\section{Correction to: Cell Death \& Differentiation} https://doi.org/10.1038/s41418-019-0427-1

Following publication of the article, the authors requested the addition of the following acknowledgement:

We would like to thank Drs Dan Pan and Zhong Zheng at the University of California, Los Angeles for their excellent technical assistance and scientific input. This study was supported by the NIH-NIAMS (grants R01AR066782, R01AR068835, R01AR061399), NIH-NIDCR (grant K08DE026805), UCLA/NIH CTSI (grant UL1TR000124), the National Aeronautical and Space Administration ("NASA", GA- 2014-154), the National Natural Science Foundation of China [81670972, 81400538], and the Zhejiang Provincial Natural Science Foundation of China [LY19H140002].

This has been corrected in the PDF and HTML versions. 